\title{
Psychopathology of Time in Brain Disease and Schizophrenia
}

\author{
JOHN CUTTING and HERTA SILZER \\ Bethlem Royal Hospital, Monks Orchard Road, Beckenham, Kent BR3 3BX,UK
}

\begin{abstract}
The literature on disturbance of time-sense in brain disease and schizophrenia is reviewed and the subjective experience of altered time-sense reported by 45 out of 350 personally interviewed schizophrenics is analyzed. A review of the literature on the effect of brain damage revealed that some phenomena (déjà vu, reduplication of time, altered tempo to events) were linked with right hemisphere dysfunction, one phenomenon (incorrect sequencing of events) was linked with left anterior brain damage, and others (disrupted "biological clock", disturbed sense of rate of flow of current or past events) could arise from subcortical as well as focal cortical damage. The sparse literature on disturbed time-sense in schizophrenia suggested that there was a shared psychopathology in this respect with right hemisphere dysfunction. The phenomena encountered in the 45 schizophrenics are described and classified.
\end{abstract}

\section{Introduction}

The psychopathology of time has been relatively neglected as a topic of investigation by neurologists and psychiatrists. Compared with, say, the volume of articles and bewildering array of terms which attempt to convey the ways in which the spatial fabric of our existence may change (Critchley, 1953; Cutting, 1990), the literature on temporal alterations to our world is meagre in the extreme. This is surprising, if only for the reason that space and time are, in a philosophical sense, equal components in our world-view. According to Kant (1787), for example, both are "necessary a priori representations which underlie all other intuitions". Or, according to Jaspers (1959), both share the quality of "investing all objectivity".

The purpose of this article is three-fold: first, to draw together a scattered literature from neurological, psychiatric and psychological sources, in the hope of establishing a correspondence between patterns of altered timesense and sites of brain damage; secondly, to draw the reader's attention to a neglected literature on the topic by German neurologists and psychiatrists between the two World Wars; thirdly, to analyze the subjective experience of time in schizophrenics. Two general theses will be argued. One is that our sense of time is just as determined by focal representations within the brain as any other quality of the external world-colour, shape, space, etc.; and that it can be selectively disrupted by brain disease just as our sense of any of these other qualities can be-as in colour agnosia, visual-object agnosia, visuospatial agnosia, respectively. A second thesis is that there are similari- 
ties between the subjective experience of time in subjects with righthemisphere brain damage and the experience of schizophrenics, an observation which supports the views of one of the authors that right hemisphere dysfunction is the underlying pathogenic substrate for schizophrenia itself (Cutting, 1990).

\section{Time-sense in neuropsychiatric practice}

\section{Range of neuropsychiatric disorders in the appreciation of time}

One of the reasons for the neglect of psychopathology of time, in our view, has been the tendency, for psychiatrists and neurologists alike, to regard disorientation in time as a non-specific indicator of cerebral dysfunction, of whatever kind and at whatever site. It is certainly true that incorrect answers to simple questions about the date do generally discriminate well between patients with an organic psychosis and those with a functional psychosis. For example, in a study of one of the authors (Cutting, 1980), comparing 74 patients with an acute organic reaction and 50 consecutively admitted patients with a functional psychosis, $36 \%$ of the former group as opposed to $4 \%$ of the latter gave the wrong year, $43 \%$ of the former as opposed to $6 \%$ of the latter gave the wrong month and $51 \%$ of the former as opposed to $18 \%$ of the latter gave the wrong day of the week. Disorientation as to year, month and day of the week may therefore be useful practical guides to the presence of recognizable cerebral dysfunction, but this rule of thumb probably obscures the fact that disorientation for time may arise for different reasons in different patient groups.

In the neuropsychiatric literature, for example, at least six discrete psychopathological entities involving time-sense can be identified (Table 1).

\section{Abnormal tempo to events}

This is the experience that real, hallucinated or subjective events are being enacted at a different speed from what would be customary.

It was reported in six out of 214 temporal lobe epileptics in Penfield's

TABLE 1. Neuropsychiatric disorders of the appreciation of time

Abnormal tempo to events

Déjà vu

Disordered sense of duration of past events

Reduplication of time

Incorrect sequencing of current events

Disordered sense of the passage of on-going time 
series (Mullan and Penfield, 1959; Penfield and Perot, 1963). In three of these, a real event was experienced at the wrong speed-slower in one, faster in another, and, in another, it had come to what the patient called "a double standstill". In the other three patients it was an hallucinated or subjective event which was experienced at the wrong speed-in two, hallucinated voices became accelerated, in one, "memories" running through her mind became "too fast to be recognized or remembered". In all six patients the lesion was right-sided, despite a roughly equal distribution of left- and rightsided foci in the 214 epileptics as a whole.

Szatmari (1937) reported a man with right-sided brain damage who experienced a visual hallucination of a horse running towards him faster than physically possible, and then experienced the horse running backwards at the same speeded-up tempo. Pichler (1943) described two patients, both with right-sided lesions, who experienced true events around them occurring faster than realistically possible. One said that everyone's movements were unduly sudden and quick. The other experienced the movements of the nurses in his hospital ward as happening so quickly that he could hardly follow them with his eyes. He commented, "Time seemed to stretch out endlessly."

The most astonishing accounts of this phenomenon, which have just come to our notice, for which we are indebted to Brown (1988), who arranged the translation of the last of these, are three detailed case-reports (Hoff and Pötzl, 1934; Pisk, 1936; Hoff and Pötzl, 1939). Hoff and Pötzl named it the "Zeitraffer" phenomenon. Literally translated this means "time-lapse" phenomenon. Time-lapse photography is a technique in which single-frame pictures are taken, at longish intervals, of things such as a flower-bud opening. In reality, the movement of such an event would be too slow to be appreciated. However, when speeded up, several days, weeks or even months can be compressed into a few seconds of film.) The choice of term is particularly apt, because, as will be seen below, subjects may not only experience an acceleration of events but may perceive movement as jerky and discontinuous.

The first case (Hoff and Pötzl, 1934) was of a man of 57 with an acute cerebrovascular accident affecting the right parieto-occipital region. (There was no postmortem, but the episode began suddenly with dizziness while defaecating, and on neurological examination he had a left homonymous hemianopia and increased tendon reflexes on the left). During the first two days in hospital he had the following experiences:

Doctors and nurses were first of all moving with a measured step, conspicuously, as if on a film. Then the tempo of things became very erratic, sometimes coming at a furious pace, "like moving pictures speeded up" as if the people involved were "running a race" ... Music, whose source was to his left, sounded very loud and very fast, as if "several radios were all blaring away together ... as if all the instruments wanted to show how much noise they could make". Sometimes, other people's speech seemed excessively fast and incomprehensible "as if the doctors and nurses were practising for a world record". However, if he were addressed directly, the rate appeared quite normal and he could understand it quite well. It was when 
someone was speaking away to the left that it sounded most peculiar-shriller, louder and faster than when away to the right.

There were other abnormal experiences-visual hallucinations, anomalous perceptions of spatial aspects of his surroundings (e.g. distortion of horizontal and vertical lines) - and the entire set of phenomena cleared within a week.

Pisk's (1936) case was of a woman of 45, with a 10-year history of psychotic experiences (tactile, visual and auditory hallucinations; delusions of control; bodily delusions) almost certainly diagnostic of schizophrenia. She was admitted to a psychiatric hospital for the first time at this stage and insulin coma treatment was commenced. During the first coma it was noted that pyramidal signs on the left half of her body could be elicited before any appeared on the right, and they were slower to disappear on the left than on the right during the recovery stage. Immediately on recovering from this coma, and for a few minutes only, she experienced the following:

"It seemed to me that everything was going on much faster than before. The nurses and the patients were moving more quickly than is usual." When the doctor spoke it sounded fast, loud and at a higher pitch.

The same experiences occurred after each subsequent coma. During one of these awakenings a rhythm was tapped out for her, and she reproduced it significantly faster. This case is not as impressive as the first, because the patient already suffered from a functional psychosis. Nevertheless, it is striking that the "Zeitraffer" phenomenon had not been present before the course of insulin coma treatment, that it lasted only a few minutes after each coma, and that the asymmetrical pattern of the pyramidal signs again points to transient right hemisphere dysfunction.

The third case (Hoff and Pötzl, 1939) is the most impressive of all, partly because of the complexity of the disordered sense of time, and partly because of the confirmation of right hemisphere damage at postmortem. The patient was 52 years old at the time of his first experience of the "Zeitraffer" phenomenon:

He suddenly felt dizzy while sitting in a cafe, staggered into the street and noticed that cars were rushing towards him from both right and left. When he looked again at one of the cars, however, he noticed that it was now moving very slowly. A passerby ordered a taxi for him, and during the trip home he continued to experience objects and people moving extremely fast ... At home a doctor was called and found that he had a left homonymous hemianopia.

This acute episode lasted only a few days and he was able to work satisfactorily for the next 10 years despite persistent hemianopia and occasional mild recurrences of the "Zeitraffer" phenomenon. Then 10 years later, while at home, he had an intense recurrence coupled with severe headache:

He called his cook who took "an infinitely long time" to move towards him. She 
appeared to be almost stationary. Simultaneously, another woman who was in the same room, situated on the patient's right, moved so quickly that he wondered if she were "wearing roller skates". Later a nurse and a doctor who were summoned moved so quickly that he felt "dizzy", but when he looked directly at them they then seemed to be standing still. He knew that they were moving, however, because their form changed as they got now nearer, then further away ... Whenever he heard a loud noise outside in the street-a passing motorcycle, for example-the acceleration in his peripheral field and the deceleration in his central field would be exaggerated. If he looked out of the window at such moments, pedestrians in the outermost field of vision seemed to be moving at a speed of about 30 m.p.h. and cars would "shoot by". At the same time, if he fixated on any of the pedestrians, they appeared to be moving along "as in a funeral procession". No-one's speech was faster or slower than usual.

The patient was admitted to hospital 2 days later and died of a myocardial infarction 3 days after this. In the meantime simple tests of object, colour and spatial perception were administered and he carried these out faultlessly. At postmortem several recent and old infarcts were found, all within the right hemisphere, scattered throughout the parietal, temporal and occipital lobes.

There are several conclusions to be drawn from these accounts. The first is that the site of the brain damage responsible for an alteration in the tempo of events was invariably in the right hemisphere. Secondly, the tempo of several concurrent events could be increased or decreased depending on which part of the visual field the events appeared in. Thirdly, visual and auditory stimuli could both be affected at the same time or either could be affected on their own.

\section{Déjà vu}

This is the experience that current and novel events have been experienced before. The first description of this as a psychopathological phenomenon is usually credited to Jackson (1889), who called it "reminiscence". Its nature was then extensively discussed by French psychiatrists and psychologists (e.g. Janet, 1903) in the early years of this century.

Examples of the déjà vu experience are as follows:

"The central feature [of my attacks] has been mental and has been a feeling of recollection, that is of realizing that what is occupying the attention is what has occupied it before, and indeed has been familiar, but has been for a time forgotten, and now is recovered with a slight sense of satisfaction as if it had been sought for ... In October 1987 I was travelling along the Metropolitan Railway meaning to get out at the fourth station... I remember reaching the second station and I then recollect indistinctly the onset of an "aura", in which the conversation of two strangers in the same carriage seemed to be the repetition of something I had previously known."

"Mother, I feel very queer, as if I'd lived this part of my life before."

(Jackson, 1890)

(Mullan and Penfield, 1959) 
A person who experiences déjà vu does not necessarily have brain disease. It is reputedly common in normal people: McKellar (1957) reported that $69 \%$ of 182 normal university students had experienced it at least once in their lives. When it does occur in someone with a demonstrable brain lesion, however, the site of this is predominantly right-sided: 9 right, 1 left (among 214 temporal lobe epileptics-Mullan and Penfield, 1959); 9 right, 4 left (among 27 temporal lobe epileptics-Cole and Zangwill, 1963); 11 right, 2 left (among 290 temporal lobe epileptics-Gupta et al., 1983).

Jamais $v u$ is usualiy considered to be the converse of déja viu. Here, a familiar and current event is not recognized as familiar:

"I knew it was my room, but I felt as if I'd never set eyes on it before."

(Reed, 1988)

Some commentators have proposed that déjà $v u$ and jamais $v u$ are not primary disturbances of time sense at all, but disorders of perception (Janet, 1903), consciousness (Lewis, 1932) or memory (Reed, 1988). The last possibility, in the case of déjà $v u$, is the least likely, in our view. Reed proposes, for instance, that the crucial psychological mechanism is a "failure to recall features of a situation which have appropriately evoked the sense of familiarity". This may be true of jamais vu, but cannot be true of déjà vu because the event is a novel one. Anyway, patients with gross amnesia, such as Korsakoff's syndrome, have difficulty in ascribing familiarity ratings to past events (Huppert and Piercy, 1976), but do not report déjà vu, and nor do patients with the déjà vu experience have gross amnesia. Janet and Lewis, however, are both substantially correct in that it must be deemed a disorder of perception, albeit of a special kind, and it is experienced in consciousness, although the fault, in our view, lies external to the consciousness-generating system itself (see Saper and Plum, 1985; Cutting, 1991). Regardless of these theoretical issues, one striking conclusion which can be drawn from the three studies on hemisphere differences quoted above is that, as with alterations in the experienced tempo of events, the déjà vu phenomenon is strongly linked with right hemisphere damage.

\section{Disordered sense of duration of past events}

Ehrenwald (1931) reported the case of a medical student who had shot himself in the right temple in an attempted suicide. The student survived, and was interviewed in hospital by Ehrenwald several weeks later, after having been transferred from another hospital where his wound had been treated surgically. At this stage, although alert and superficially free of any psychological sequelae of the brain damage, the student was found to have an isolated but grossly abnormal appreciation of the duration and timing of past events, both prior to and since his suicide bid. For example, he could not say when he had begun his medical studies, mistook the length of time he had spent in the previous hospital, and sometimes maintained he had come straight to the present hospital. Ehrenwald called this state of affairs 
"Störung der Zeitauffassung" (disturbance of the concept of time), adding that he considered it to be a "physiological agnosia for time sense".

Davidson (1941) reported two cases of what he also called "time agnosia". Both were of men who had sustained head injuries, one associated with a left hemiplegia, indicating right hemisphere damage, the other without localizing signs. Both could remember an actual event in the past, but could not say how long it had lasted, nor tie it up with other events. Wagner (1943) reported another example, also in a man with a right parietal wound.

The case reports so far quoted add further support to the conclusions reached in the cases of altered tempo to events and déjà vu that the right hemisphere has a particular role in the representation of time sense. However, not all instances of a disordered estimation of the duration or incorrect ordering of past events have isolated right hemisphere dysfunction. Van der Horst (1956) found that incorrect ordering of past events also occurred in Korsakoff's syndrome, where the critical pathology is bilateral subcortical damage involving the mamillary bodies and dorsomedial nuclei of the thalamus. And Richards (1973) reported that the celebrated patient H.M., whose gross amnesia resulted from bilateral temporal damage, had a retrograde amnesia of 2 years, but estimated the gap in his memory as only a few hours. There are, however, counter-examples. Schilder (1936), for example, mentioned a patient with a memory loss of one month, who knew that about a month had passed since his last recollection. Brown (1988) noted that the patients with Korsakoff's syndrome that he interviewed were "usually fairly accurate" in estimating the length of their hospital stay. It may also be that the pattern to the inaccurate estimation of duration of past time in patients with subcortical damage is qualitatively different from that which occurs with right-sided cortical damage. Spiegel et al. (1956), for example, reported a relatively isolated form of inaccurate estimation of duration of past time in patients who had recently undergone. bilateral thalamotomy. But such patients consistently judged past time as shorter than it really was, a pattern which is not mentioned as characteristic in the above reports of patients with right hemisphere damage. One woman, for example, came round from the operation feeling several years younger. Another felt that each day was finished by mid-morning, although she knew that this could not be true.

In summary, inaccurate estimation of the duration of past events does not appear to be so closely linked with right hemisphere dysfunction as do the experiences of altered tempo to events and déjà vu. Nevertheless, in the absence of subcortical damage, the phenomenon, from the few case reports available, does seem to be more often linked with right than with left hemisphere damage.

\section{Reduplication of time}

This was first described by Weinstein et al. (1952) as a comparable phenomenon in the temporal sphere to reduplicative paramnesia (Pick, 1903 ) in the spatial domain. Whereas someone with reduplicative paramne- 
sia believes that they are simultaneously in two or more identical or virtually identical places, someone with reduplication of time "believes that they simultaneously exist in not only the present but also in a duplicate time" (Joseph, 1986). In fact, the two examples given by Weinstein and colleagues from among 11 patients with the purported phenomenon were not reduplication for time, as Joseph correctly defined it. One man believed that the patient in the bed opposite had worked in his garage many years ago, and a woman believed that her attending doctor was an insurance salesman she had known as a young woman in her home town. Both these patients had right hemisphere damage, but their problem itself is better regarded as misidentification of person. Joseph's own two cases are, however, true to his own definition, and it is unfortunate that he does not record the site of brain damage in either. The commoner delusional misidentification phenomena, however-Capgras' syndrome, reduplicative paramnesia-have strong links with right hemisphere damage (Feinberg and Shapiro, 1989), and it is likely that reduplication of time also has this link.

\section{Incorrect sequencing of current events}

Head (1920) and Kleist (1935) both made the clinical observation that aphasic patients with a left anterior lesion had difficulty in placing two successive events occurring in the present in the correct order. Efron (1963) confirmed this experimentally by showing that patients with left anterior brain damage with aphasia were impaired at deciding which of two differently coloured lights or two different tones, displayed in rapid succession, had come first. The dominance of the left hemisphere in this respect was underlined when he presented electric shocks, either simultaneously or with a 4-6 msec delay, to right and left index fingers in normal subjects. When the left index finger was stimulated $4-6$ msec before the right index finger a subject would report that the two stimuli were simultaneous, and when the fingers were really stimulated simultaneously a subject would report that the stimulus to the right finger preceded the one to the left. This indicated that the "observer in their brain" (as he put it) for this task was "located somewhere to the left of the midline because it took the neural message delivered to the right hemisphere $4-6 \mathrm{msec}$ longer to reach it" (Efron, 1990).

Unlike the four abnormal time-sense phenomena considered earlier, therefore, incorrect sequencing of current events is strongly linked with left hemisphere damage.

\section{Disordered sense of the passage of ongoing time}

This is the most extensively studied of all the time-sense phenomena. Fraisse (1964) summarizes the literature on normal subjects to that date, which shows that the time interval studied, the age and sex of the subject, whether the time is "filled" or "unfilled", and several other factors all affect the results. For these reasons the situation with regard to the effect of cerebral dysfunction is unclear. The most consistent finding is that drug intoxication, 
particularly with cannabis, LSD or mescaline (Melges, 1982), leads to an overestimation of the passage of time, i.e. intervals appear longer than they really are. There are no studies, to our knowledge, on the effect of unilateral brain damage.

\section{Time-sense in schizophrenia: literature}

The literature on time-sense in schizophrenia is distinctly meagre. There are a handful of psychological studies examining the ability of schizophrenics to estimate the passage of time (e.g. Rabin, 1957; Orme, 1966; Wahl and Sieg, 1980), but these were merely designed to establish whether schizophrenics under- or over-estimated the passage of time. Even this question was not decisively answered, as overall the studies provided conflicting results on this issue. We are here more concerned with phenomenological accounts of disordered time-sense in the condition, and the literature on this is largely accounted for by the contributions of five authors: Fischer (1929), Lewis (1932), Minkowski (1933), Horanyi-Hechst (1943) and Petho (1985).

Fischer's article is the most comprehensive and detailed. He reported abnormal experiences of time in seven schizophrenics. The following are the most illuminating extracts from each case:

Case 1: "Sometimes when the people come at night they bite my head off, nasty folk, and then they lay down male and female heads, side by side ... What's happened to my head ... Where it was, between the shoulders, right here, has become a clock, a machine. Now I'm making time myself, a new time, how it really should be. The machine is square, black and white, and all muddled up. Thus it is, and pointing in the four directions of Heaven. The new time is made so, turning round, produced by the black and white machine."

Case 2: "I was looking through a book of African art one day, in a state of some consternation. The stark images depicted there intensified my own inner feelings of emptiness and inertia ... Suddenly I was overcome by a state of mind which I had never experienced before: my arms and legs seemed to be extending in length and swelling up. I felt an excruciating pain in my head and time stood still ... Then time seemed to flow again as before and I was again in touch with everyday things as they were. But the experience that I went through, when time stood still, was like some sort of gate in my life, through which I had to pass to achieve a new state of mind."

Case 3: "Ah, this life, how can I bear it ... There's nothing at all inside me; I'm as cold as a piece of ice, frozen to the core ... Outside, when I look out of my window, everything looks strange; there seems to be so much going on, and all happening so quickly ... but I don't seem to belong to it any more. Whereas I feel as if I'm frozen in winter-time, the world itself goes by in its usual way-spring, summer, flowers blooming. In fact the seasons seem to be rushing headlong, one after another-spring, summer, autumn."

Case 4: "Yesterday, at midday, when the meal was being served, I looked at the clock. There was something odd about it, because it no longer gave me any help; it told me nothing. How could I reconcile myself to this? I felt as if I were being transported back in time, as if something that had gone before was returning, as if I were retracing some previous path. It seemed to me that when it was really half past 
eleven it had become 11 o'clock. But it wasn't just that the same time had come round again, it was also a sense that it was secondhand ... In the middle of all this, something else happened. It was now no longer 11 o'clock, but some long-past era. It was all so strange that I thought someone must have played a trick with time. And then the most peculiar thing of all happened-a completely new kind of time emerged."

Case 5: "I'm living in eternity. There are no hours, no midday, no nights. Outside things go on as before-leaves blow around, trees move in the wind, other people come and go. But for me time does not move. The clock is exactly the same, but time stands still ... What about the future? It's impossible to reach it. I can tell you about the present and the past, but I can't really imagine them. I can't picture them, and yet I'm sinking into the past. Everything is a question mark."

Case 6: "There is no present any more, only a sense of the past. Is there a future? There used to be, but now it is shrinking. The past is so obtrusive ... I'll give you an example of what it's like. I'm like a machine, which stands in one place only, working away, yes, but one which tears everything to shreds ... Or else I'm like a flaming arrow which can only go backwards."

Case 7: "Time stood still. Then it became different. Then it disappeared entirely ... Then a new time emerged. This new time was endless, more manifold than the previous one, hardly deserving the name 'time', as we know it. Suddenly it came to me that this time did not only lie in front of and behind me, but spread out in all directions."

A complete qualitative change in the experience of time is evident in these extracts. It is not just going faster or slower, but stops, goes backwards and is even transposed into a new and alien dimension.

Lewis identified several "distinctive features" of schizophrenic timesense. First of all he noted the theme of a "feeling of previous death and rebirth":

"I should say it was the beginning of a new world ... I think there has been a break in my life ... It seems as if $\mathrm{I}$ have died ... I think I shall die at a certain time and live again."

"A feeling of an interruption time" was also common:

"People's faces seem to open up to me fresh every time. I seem to have to arouse myself and accept the world again every moment. I have no continuity in my way of seeing things."

Then there was what he referred to as "thinking backwards":

"Whenever anyone said anything to me, it referred back to some part of my life ... One mind was living back and one mind forward."

Finally, he pointed out the frequency of "premonitions", "anticipations" and "prophecies" about the future:

"Before a door opens, I know it's going to happen."

"I've noticed that when I do anything or when I'm going to do anything, people seem to imitate me." 
Minkowski was so impressed with the alteration of time-sense in schizophrenia that he fashioned his entire theory of the condition around this single phenomenon. To him the most characteristic feature of schizophrenia was what he called "a lack of vital contact with reality", in which an altered appreciation of time was the major component:

"I am always looking for immobility," one of his patients reported. "I tend towards rest and immobilization. I also have within me a tendency to prefer immobility in the things around me-immovable objects, boxes, bolts, things that are always there, which never change ... A train goes past on the embankment; the train doesn't exist for me; I want only to build the embankment."

Horanyi-Hechst reviewed the various types of altered time-sense that he had encountered in his schizophrenic patients, giving examples of each. Although he gives much less detail than Fischer did for each of the phenomena, he attempts a classification of the entire range, which Fischer did not. First, he concludes that "innate biological rhythms" or "primitive time-sense" is not affected in schizophrenia. This aspect of time, also referred to as the "biological clock" (e.g. Gooddy, 1959), has not so far been mentioned in this article, as the brain structures purportedly involved are subcortical, particularly the hypothalamus, and only conditions which damage these structures, such as global degenerative processes or encephalitis lethargica, can affect these rhythms, leading, for example, to day-night reversal in wakefulness. Horanyi-Hechst's second category of phenomena is what he calls Zeitgefühl-the feeling for time or the estimation of duration between two separate points in time. He then notes that this involves a decision as to which of two events comes first, sequencing of current events in our scheme (Table 1), which he claims is unaffected in schizophrenia, as well as an estimation of duration, sense of the passage of on-going time in our scheme (Table 1), which he says is affected in the condition. He then illustrates the latter problem with the case of a schizophrenic who thought 24 hours had passed when in reality only 2 hours had gone by, and with the case of another schizophrenic who experienced the "Zeitraffer" phenomenon, a term which he actually uses and whose original description by Hoff and Pötzl he acknowledges. Horanyi-Hechst's patient:

experienced the movements of things around her as unduly fast and also experienced her own movements in relationship to the movements of things in her environment as accelerated.

The third category of disordered time-sense phenomena suggested by Horanyi-Hechst is what he calls "chronagnosia", or disordered sense of duration of past events in our scheme in Table 1. He believes this is rarely encountered in schizophrenia, unlike Korsakoff's syndrome where he admits it is common, but notes, in agreement with Minkowski, that a "chronagnosia" with respect to future events is common in schizophrenia. His final category is what he calls a disorder of "time consciousness" or "dynamic temporalization", in which a subject loses the sense of continuity of time. This, according to Horanyi-Hechst, is common and gives rise to the most distressing experiences of all: 
"Everything around me is stationary; there is no future, no past; I have become an absolute being."

Last of those whom we regard as making original contributions to the psychopathology of time in schizophrenia is Petho, whose description of what he calls "chronophrenia" introduces yet another element. This author reported a woman who was studied in his clinic for 12 years between the ages of 25 and 37. Although Petho did not regard her as schizophrenic it is difficult to see what other diagnosis she could be given because she had "voices", a "belief in a telepathic influence", "incoherent thinking" and is described as "devoid of colour affectively". Her disordered time-sense included déjà $v u$ ("I can't escape the feeling that these things have already happened to me") but in addition there was a persistent belief that everything that happened to her was not only familiar but had actually been experienced in another life. Petho uses the word "reduplication" and this is exactly what his patient experienced-a reduplication of every event, current, past and future. The complications that this produced in her life were enormous: for example, when she and her husband (the marriage only lasted 4 years) were building a house she would not allow one of the walls to be built in the planned place because, as she said, "That wall was there in my previous life and it caused trouble then too." She was asked if she wanted to go to the 1976 Olympic Games and replied, "It could happen that I will go; I have a memory of it. But I also have a memory that I won't go to those Games so that that memory won't come back to me."

Two general points emerged from the literature on schizophrenic timesense, when compared with that of subjects with identifiable forms of brain damage. First, there does appear to be a shared psychopathology: the "Zeitraffer" phenomenon, déjà vu, reduplication of time, and a disordered sense of the passage of on-going time occur in both. Secondly, however, there are some aspects of a schizophrenic's experience of time which are not mentioned in the brain damage literature, and there are some aspects of a brain-damaged subject's experience which are either not mentioned or specifically noted as rare in schizophrenia. What appears unique about the schizophrenic's experience is its pervasiveness, the bitterness with which it is expressed and the emphasis on a discontinuity of time. The features distinguishing the brain-damaged subject's experience or behaviour from a schizophrenic's are impaired sequencing ability, disruption to the "biological clock" and, to a certain extent, inaccurate estimation of duration of past events. It is significant, in our view, that three of the four shared psychopathological phenomena-- "Zeitraffer" phenomenon, déjà vu, reduplication of time-are strongly linked with right hemisphere damage. On the other hand, none of the three phenomena which are largely confined to those with brain damage-impaired sequencing, disruption to "biological clock", inaccurate estimation of past durations-are specifically linked with right hemisphere damage, and one of these-impaired sequencing - is specifically linked with left hemisphere damage.

In order to pursue this thesis we collected accounts of abnormal timesense from a group of schizophrenics seen personally by one of the authors over a number of years. 


\section{Time-sense in schizophrenia: personal series of patients}

The sample of schizophrenics comprised 350 subjects-all diagnosed according to the Research Diagnostic Criteria of Spitzer et al. (1975). They were seen over a period of 17 years and comprise all those schizophrenics admitted under the care of J.C. during this period or interviewed by him at the request of other psychiatrists. Clearly the sample is not representative of a geographically homogeneous population of schizophrenics, but the large sample size at least ensures that relatively rare time-sense phenomena would not be missed. The unrepresentativeness of the sample, however, means that the exact prevalence of any phenomenon cannot be guaranteed. One hundred patients were chronic, in that marked symptoms of schizophrenia had persisted despite at least 2 years of adequate doses of neuroleptic medication. The remaining 250 subjects had acute (under 3 months--160), subacute ( 3 months to 1 year--43), subchronic ( 1 to 2 years-13) or chronic (over 2 years without adequate medication-34) illnesses.

Not all subjects were specifically asked about their experience of time. (The earliest 46 patients of the series were not specifically asked about this).

TABLE 2. Disordered sense of time in 350 schizophrenics

Disordered sense of the rate of flow of on-going time

(abnormal tempo to events, inaccurate estimation of duration between two separate points in time including the present)

Speeding up of time

Slowing down of time

Losing track of flow of time

"Zeitraffer" phenomenon

Disordered sense of the rate of flow of past events

(time agnosia, chronagnosia, age disorientation, inaccurate estimation of the duration of past events)

Marked disorientation or false conviction about year or age 5

Disordered sense of continuity and uniqueness of time

(déjà vu, jamais vu, reduplication of time, new dimension appearing, obtrusiveness of past)

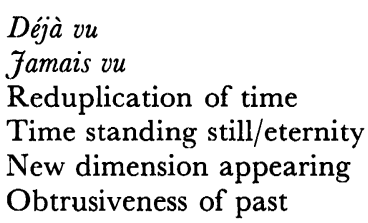

\section{5}

1

2

3

N.B.

1. Three patients reported that time had changed in an unspecified way but would not or could not elaborate.

2. No patient reported problems in sequencing events.

3. No patient was observed to have grossly disordered night-day rhythms. 
This further reduces the representativeness of the sample, but these patients are included because several of them mentioned abnormal time-sense phenomena spontaneously.

The various phenomena which were elicited are shown in Table 2. The three-part classification employed is based on Horanyi-Hechst's suggestion-see above. No patient had any phenomena attributable to his first category-disordered "biological clock". But Horanyi-Hechst's remaining three categories appeared to accommodate all the phenomena which were encountered, and the only modifications we have made is to the name of each. The categories listed in Table 1 are redistributed in Table 2 according to the following principles. The essence of the first category in Table 2, in our view, is a quantitative disturbance in the rate of flow of on-going time. It is true that one of the elements in the "Zeitraffer" phenomenon is a sense of discontinuity in time, whereby events appear jerky, and this phenomenon might equally well be placed in the third category. However, acceleration and deceleration of events are its more prominent manifestations and it is provisionally placed in category 1 . The essence of the second category is similar to the first, except that the time period covered is the past rather than the present, and as different factors may be responsible for estimating past flow of time than for present flow, particularly if the time covered predated the onset of the illness, this seems to us to deserve a separate category. The third category is the most difficult to define, but it represents a qualitative breakdown in two of the most fundamental and incontrovertible properties of time-continuity and uniqueness. Whatever else time is it is continuous and unique, whereas the general flavour of the most bizarre experiences of schizophrenics, well illustrated in Fischer's accounts, suggests a discontinuity and lack of uniqueness of time. Finally, there is the issue of impaired sequencing of events. Horanyi-Hechst included this in both categories 1 and 2 of Table 2, as it enters into decisions about the flow of on-going and past time. Because of its specific link with left hemisphere damage-discussed above--it seems to us that it is a special category, but as none of the schizophrenic patients reported this, it is not included in the Table. (Lewis' observations on premonitions and delusions about rebirth were not included, because, in practice, such beliefs were so intimately connected with delusions about the self that a temporal component was difficult to isolate).

\section{Disordered sense of the rate of flow of on-going time}

A sense that time was speeded up was the commonest single phenomenon: "days went quickly"; "months and years passed easily"; "speeded up, not enough time to get on with things"; these were typical remarks about this phenomenon. A sense that time was passing more slowly was less common. Some patients reported that they had lost track of time, e.g. "I didn't know what time of day it was"; "I lost track of time completely". Four patients had experienced one or more elements of the Zeitrafferphenomenon:

"It was as if time were moving very slowly or very quickly. I felt I was moving 
normally and everyone was moving slowly, and if I speeded up I would look like a Charlie Chaplin movie."

"Time wasn't moving slowly, but in jerks."

"I noticed that stationary cars appeared to be coming towards me."

"Things were coming either quickly or slowly and I was speeding everywhere I went."

\section{Disordered sense of the rate of flow of past events}

Four patients were inaccurate about their age or the year by a margin of over a decade: 1950 instead of 1978; 1934 instead of 1978; aged 32 instead of 62 ; aged 78 instead of 62 . All these four had chronic illnesses and had all been continuously in the same hospital for over 30 years. One patient, with a relatively acute illness, insisted the year was 1988 when it was in fact 1984, and stuck to her belief despite considerable attempts on my part to persuade her she was wrong.

\section{Disordered sense of the continuity and uniqueness of time}

Déjà $v u$. The experience of déjà $v u$ in five patients may not seem so remarkable in view of its frequent occurrence in normal subjects (see above). In all five patients, however, it was not a fleeting experience, but one which was quite pervasive and carried considerable conviction. In one of the five it was part of a complex distrust of all the usual sources of time-sense:

"Well you know Dr Who [a television science fiction character] has got a Tardis [his spaceship which could go forwards and back in time]. And you know that it can go back to the same time again and again. Well, it was like that. I kept going back to the same moment. It all seemed a waste of time. I kept going back for proofs. I felt I'd done it all before." (He would not accept the date on any newspaper published in London, but was happy to accept it if it was printed on a newspaper published outside London. He remembered as a boy being taken to a celebrated beauty spot to the South of London where his father had pointed out on a fallen tree how you can tell a tree's age. He felt that if only he could find that tree again then he would again be sure of the date).

Famais $v u$. One patient experienced jamais $v u$ as part of a complex disorganization of his time-sense:

"There were feelings of a temporal change in the development of things, in the way things take place time-wise. Time is sequential. Just what happens around one gives one's original memory of objects and qualities of objects. So everything I saw was just as if I'd visited a place for the first time, when in fact I'd experienced it before."

Reduplication of time. Two patients held a complex set of delusions which included the belief that either a double (in the case of one man) or the 
descendants from a previous life (in the case of a young woman) had a separate and not entirely contemporaneous existence in some other part of the world. The ramifications of these beliefs were hard to follow, and internally inconsistent, but they conformed partly to the definition of reduplication of time given above. They were not as true to the definition as those of the patient described by Petho, but because the parallel existences were not contemporaneous they could not be strictly regarded as instances of reduplicative paramnesia either. The woman, in fact aged 22, believed that she had started life 50 years ago as a plant or a seed, had then become an animal and then a human. She believed that her descendants from her life as a plant were still living and she would wake up in a frantic state during the night worrying about whether they--seeds or plants-could breathe properly. The man believed that his real self had been separated from the person that he now was at birth and that his real self inhabited a different world from "him" - certainly outside London where "he" now lived and probably in a different dimension of time.

Time standing still/eternity. Three patients reported this experience:

"Time stood still. Time was frozen. I looked at a clock and it didn't mean anything."

"Time seemed to be infinity. I thought I was controlling time."

"I lost all touch with time because I wasn't sleeping. The whole time system in my body went caput. Time seemed like an eternity. Time stood still."

New dimension of time appearing. One patient, who also felt time was infinity, experienced the re-emergence of a new dimension of time:

"Time seemed to be infinity ... I thought I was here and in a different dimension at the same time."

Obtrusiveness of past. Several patients appeared preoccupied with the past to such an extent that the present hardly impinged on them. In two of these a disordered sense of time seemed the primary problem:

"Time seemed like I was back in the past, not today's time."

"I'm not sure if time slowed down or speeded up. Certainly something happened to it, because I was lying on my bed one day and reality somehow passed inwards ... I became more interested in memory than perceiving reality around me, interested in doing things and being places which brought out my memory rather than seeking new experiences."

\section{Discussion}

The psychopathology of time is without doubt a difficult subject to grapple with. There is no acceptable psychological model to underpin any logical 
classification of the various normal and abnormal phenomena, and a neuropsychological approach to the topic has only just begun (Brown, 1988; Efron, 1990). This article has drawn together strands from two literaturesthat on time-sense in subjects with recognizable brain damage and that on schizophrenic time-sense. The most striking finding to emerge from the brain-damage literature was the strong link between right hemisphere damage and certain of the psychopathological phenomena-particularly those, such as déjà $v u$ and reduplication of time, which involve a loss of the sense of continuity and uniqueness of time. The most striking finding from the schizophrenic literature was the overlap between the experience of schizophrenics and those with right hemisphere damage in certain respects.

These two points lend some support to the hypotheses put forward at the beginning of this article: (1) that our sense of time does have a focal representation within the brain, or at least that some parts of the brain are more concerned with certain specific temporal matters than others; and (2) that the existence of a shared psychopathology between schizophrenics and those with right-sided brain damage suggests that the former condition may itself be a consequence of right hemisphere dysfunction.

A detailed discussion of both these issues can be found in Cutting (1990). In brief, an explanation for the former first requires an appreciation of the latest evidence concerning hemispheric distribution of functions. The verbal-nonverbal dichotomy, originally formulated by Milner (1958) to account for what she saw as the chief differences between the left and right hemispheres respectively in the way they tackled perceptual and memory tasks, is now generally admitted to be incorrect. Of the models which have been put forward as replacements, the most comprehensive and accurate, in that it can explain the greatest number of experimental findings, is that of Kosslyn (1987). He suggests that the left hemisphere is adept at representing categories of things, whether verbal or nonverbal, whereas the right hemisphere possesses the apparatus to represent individual members. of such categories - also either verbal or nonverbal-and hence is concerned with identity or uniqueness. As the uniqueness of a thing is partly accounted for by the temporal and spatial context in which it appears, a logical corollary of Kosslyn's argument is that the right hemisphere should play a particular role in representing the temporal and spatial qualities of the world. That this is so in the case of the spatial fabric of our existence is incontrovertible: the superior role of the right hemisphere vis-à-vis the left in visuospatial matters has been convincingly demonstrated in numerous publications since Pötzl (1928), Lange (1936) and Brain (1941) first pointed this out. The right hemisphere's possible superiority vis-à-vis the left in representing temporal matters (with the exception of simple sequencing) has not been so far considered, but the evidence presented in this article should, we hope, lead to a gradual appreciation of the significance of the link between right hemisphere and time.

On the issue of right hemisphere dysfunction and schizophrenia, it is the contention of one of the authors that the evidence for such a link is considerable (Cutting, 1990). There is a school of opinion, originating with 
Flor-Henry (1969), that left hemisphere dysfunction is the crucial neuropsychological substrate, but, in our view, the evidence for this is flimsy, and much of it is consistent with over-activity of the left hemisphere relative to the right, not under-activity, as Flor-Henry maintains. As a small contribution to the debate, it seems to us that the evidence on time-sense in schizophrenia discussed in this article gives further support to the righthemisphere-dysfunction hypothesis, and certainly no support to the lefthemisphere-dysfunction hypothesis.

\section{References}

Brain, W. R. (1941). Visual disorientation with special reference to lesions of the right cerebral hemisphere. Brain, 64, 244-272.

Brown, J. W. (1988). "The Life of the Mind." Lawrence Erlbaum, Hillsdale, NJ.

Cole, M. and Zangwill, O. L. (1963). Déjà vu in temporal lobe epilepsy. Journal of Neurology, Neurosurgery and Psychiatry, 26, 37-38.

Critchley, M. (1953). "The Parietal Lobes." Hafner, New York.

Cutting, J. (1980). Physical illness and psychosis. British Fournal of Psychiatry, 136, 109-119.

Cutting, J. (1990). "The Right Cerebral Hemisphere and Psychiatric Disorders." Oxford University Press, Oxford.

Cutting, J. (1991). Neuropsychiatric aspects of attention and consciousness: delirium, stupor and coma. In "Textbook of Neuropsychiatry," 2nd edn (Eds S. C. Yudofsky and R. E. Hales), in press. American Psychiatric Press, Washington.

Davidson, G. M. (1941). A syndrome of time-agnosia. Journal of Nervous and Mental Diseases, 94, 336-343.

Efron, R. (1963). Temporal perception, aphasia and déjà vu. Brain, 86, 403-424.

Efron, R. (1990). Personal communication.

Ehrenwald, H. (1931). Störung der Zeitauffasung, der raumlichen Orientierung, des Zeichnens und des Rechnens bei einem Hirnverletzten. Zeitschrift für die gesamte Neurologie und Psychiatrie, 132, 518-569.

Feinberg, T. E. and Shapiro, R. M. (1989). Misidentification-reduplication and the right hemisphere. Neuropsychiatry, Neuropsychology and Behavioural Neurology, 2, 39-48.

Fischer, F. (1929). Zeitstruktur and Schizophrenie. Zeitschrift für die gesamte Neurologie und Psychiatrie, 121, 544-574.

Flor-Henry, P. (1969). Psychosis and temporal lobe epilepsy: a controlled investigation. Epilepsia, 10, 363-395.

Fraisse, P. (1964). "The Psychology of Time." Eyre \& Spottiswoode, London.

Gooddy, W. (1959). Time and the nervous system: the brain as a clock. Lancet, ii, 1155-1156.

Gupta, A. K., Jeavons, P. M., Hughes, R. G. and Covanis, A. (1983). Aura in temporal lobe epilepsy: clinical and electroencephalographic correlation. Fournal of Neurology, Neurosurgery and Psychiatry, 46, 1079-1983.

Head, H. (1920). "Studies in Neurology." Frowde, London.

Hoff, H. and Pötzl, O. (1934). Über eine Zeitrafferwirkung bei homonymer linksseitiger Hemianopsie. Zeitschrift für die gesamte Neurologie und Psychiatrie, 151, 599-641.

Hoff, H. and Pötzl, O. (1939). Time acceleration in brain disease. In "Agnosia and Apraxia: Selected Papers of Liepmann, Lange and Pötzl”. (Ed. J. W. Brown) Lawrence Erlbaum, Hillsdale, 1988

Horanyi-Hechst, B. (1943). Zeitbewusstsein und Schizophrenie. Archiv für Psychiatrie, 116, 287-292.

Huppert, F. A. and Piercy, M. (1976). Recognition memory in amnesic patients: effect of temporal context and familiarity of material. Cortex, 12, 3-20.

Jackson, J. H. (1889). On a particular variety of epilepsy ("intellectual aura"), one case with symptoms of organic brain disease. Brain, 11, 179-207.

Janet, P. (1903). "Les Obsessions et la Psychasthénie." Vol. 1. Alcan, Paris. 
Jaspers, K. (1959). "General Psychopathology," 7th edn. Trans. by J. Hoenig and M. W. Hamilton, 1963. Manchester University Press, Manchester.

Joseph, A. B. (1986). Focal central nervous system abnormalities in patients with misidentification syndromes. Bibliotheca Psychiatrica, 164, 68-79.

Kant, I. (1787). "Kritik der reinen Vernunft." Trans. by N. K. Smith, 1968. Macmillan, London.

Kleist, K. (1935). "Gehirnpathologie.” Barth, Leipzig.

Kosslyn, S. M. (1987). Seeing and imagining in the cerebral hemispheres. Psychological Review, 94, 148-175.

Lange, J. (1936). Agnosien und Apraxien. In "Handbuch der Neurologie," 6 Band (Eds O. Bumke and O. Foerster), p. 848. Springer, Berlin.

Lewis, A. (1932). The experience of time in mental disorder. Proceedings of the Royal Society of Medicine, 25, 15-24.

McKellar, P. (1957). "Imagination and Thinking." Cohen and West, London.

Melges, F. T. (1982). "Time and the Inner Future." J. Wiley, New York.

Milner, B. (1958). Psychological defects produced by temporal lobe excision. Research Publications of the Association for Research in Nervous and Mental Disease, 36, 244257.

Minkowski, E. (1933). "Le Temps Vécu." Reprinted 1968, Delachaux and Niestlé, Neuchâtel.

Mullan, S. and Penfield, W. (1959). Illusions of comparative interpretation and emotion. Archives of Neurology and Psychiatry, 81, 269-284.

Orme, J. E. (1966). Time estimation and the nosology of schizophrenia. British fournal of Psychiatry, 112, 37-39.

Penfield, W. and Perot, P. (1963). The brain's record of auditory and visual experience. Brain, 86, 595-696.

Petho, B. (1985). Chronophrenia-a new syndrome in functional psychoses. Psychopathology, 18, 174-180.

Pichler, E. (1943). Über Störungen des Raum- und Zeiterlebens bei Verletzungen des Hinterhauptlappens. Zeitschrift für die gesamte Neurologie und Psychiatrie, 176, 434-464.

Pick, A. (1903). On reduplicative paramnesia. Brain, 26, 260-267.

Pisk, G. (1936). Über ein "Zeitraffer" phänomen nach Insulinkoma. Zeitschrift für die gesamte Neurologie und Psychiatrie, 156, 777-786.

Pötzl, O. (1928). "Die optisch-agnostischen Störungen." Deuticke, Leipzig.

Rabin, A. I. (1957). Time estimation of schizophrenics and non-psychotics. Fournal of Clinical Psychology, 13, 88-90.

Reed, G. (1988). "The Psychology of Anomalous Experience." Prometheus Books, Buffalo, NY.

Richards, W. (1973). Time reproduction by H.M. Acta Psychologica, 37, 279-282.

Saper, C. B. and Plum, F. (1985). Disorders of consciousness. In "Handbook of Clinical Neurology," Vol. 45 (Ed. J. A. M. Frederiks), pp. 107-128. Elsevier, Amsterdam.

Schilder, P. (1936). Psychopathology of time. Journal of Nervous and Mental Diseases, 83, 530546.

Spiegel, E. A., Wycis, H. T., Orchnik, C. and Freed, H. (1956). Thalamic chronotaraxis. American Fournal of Psychiatry, 113, 97-105.

Spitzer, R. L., Endicott, J. and Robins, E. (1975). "Research Diagnostic Criteria." New York State Psychiatric Institute, New York.

Szatmari, A. (1937). Über optische Sinnestäuschungen als epileptisches Äquivalent bei traumatischer Schadingung des Hinterhauptlappens. Archiv für Psychiatrie und Nervenkrankheiten, 107, 290-299.

Van der Horst, L. (1956). Le sens de la temporalisation pour la memoire et pour l'orientation. Évolution Psychiatrique, 189-205.

Wagner, W. (1943). Anisognosie, Zeitrafferphänomen und Uhrzeitagnosie als Symptome der Störungen im rechten Parieto-Occipitallappen. Nervenartz, 16, 49-57.

Wahl, O. F. and Sieg, D. (1980). Time estimation among schizophrenics. Perceptual and Motor Skills, 50, 535-541.

Weinstein, E. A., Kahn, R. L. and Sugarman, L. A. (1952). Phenomenon of reduplication. Archives of Neurology and Psychiatry, 67, 808-814. 


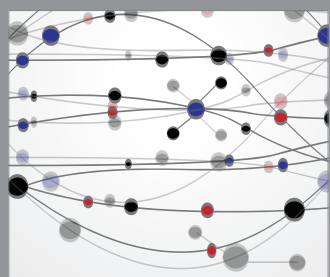

The Scientific World Journal
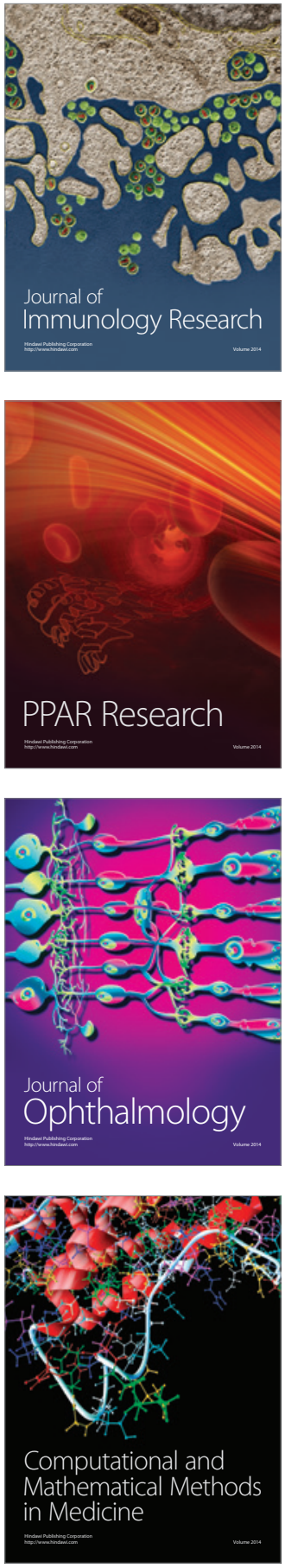

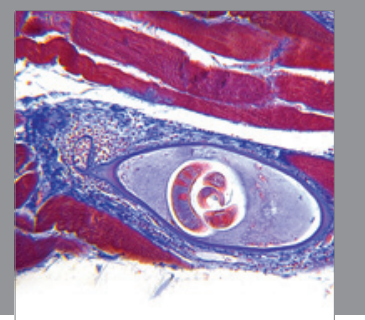

Gastroenterology

Research and Practice
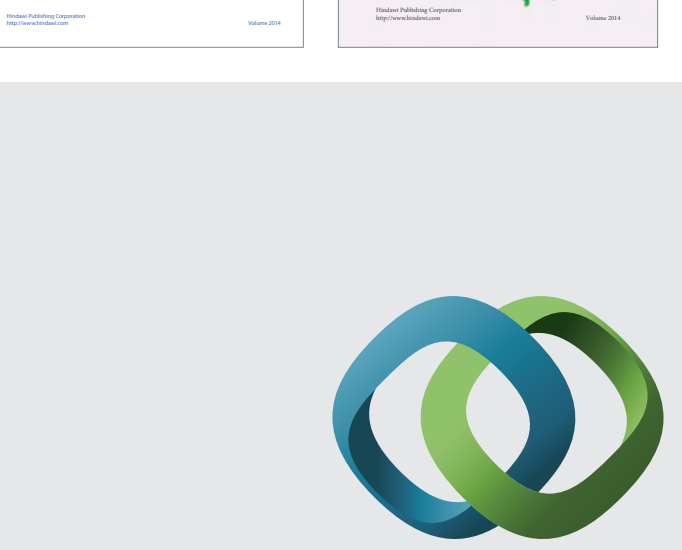

\section{Hindawi}

Submit your manuscripts at

http://www.hindawi.com
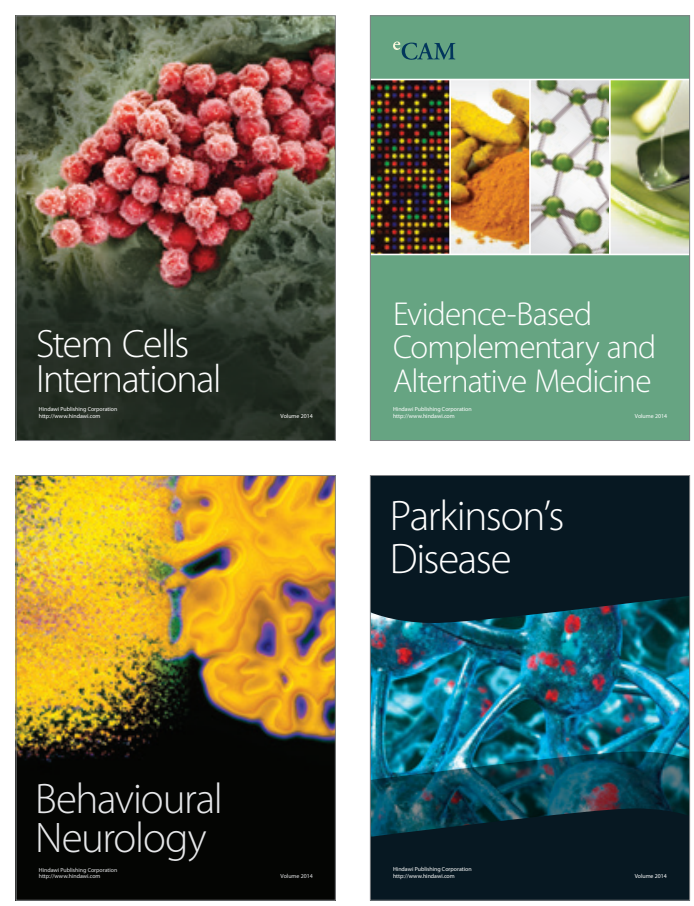

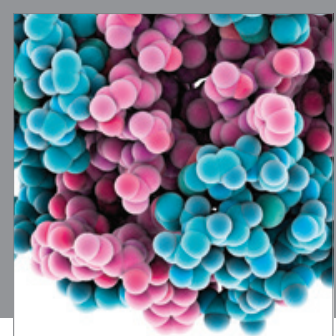

Journal of
Diabetes Research

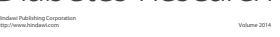

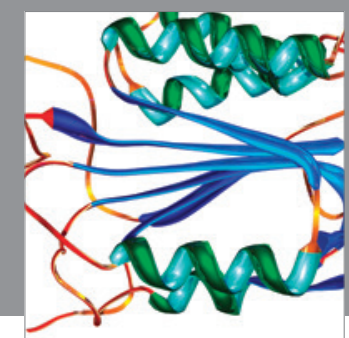

Disease Markers
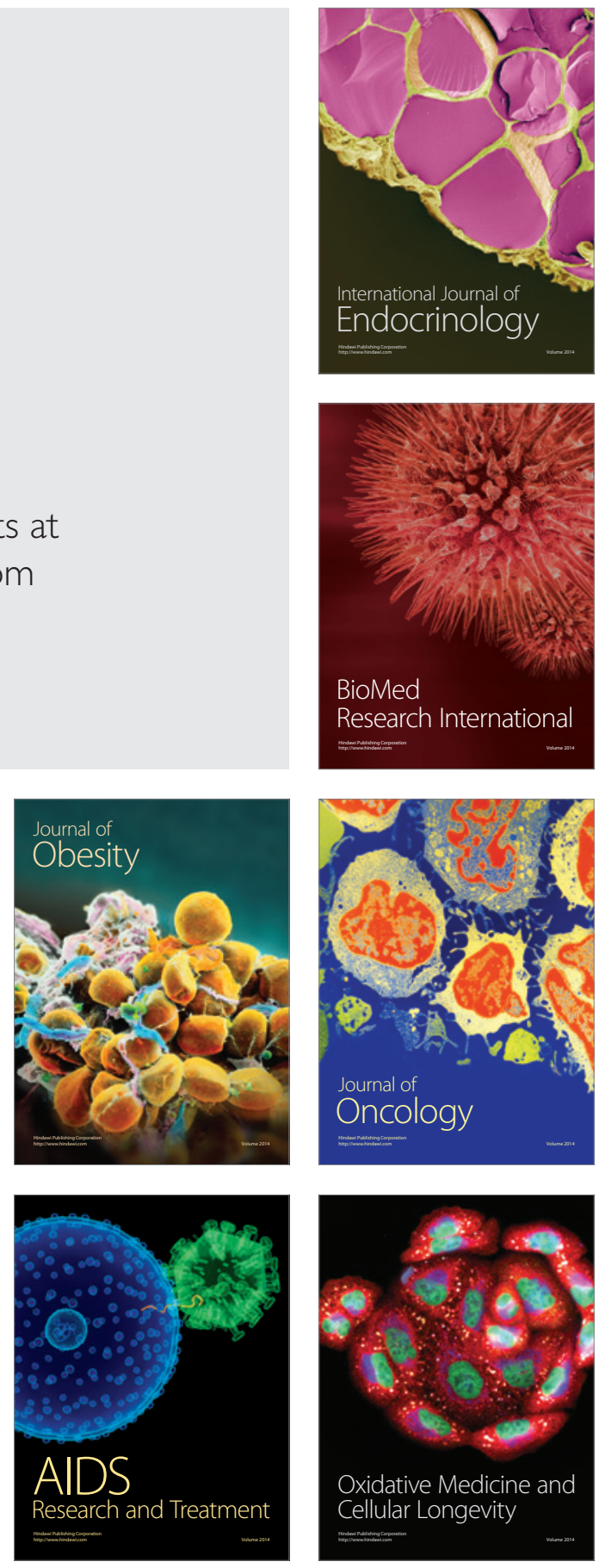